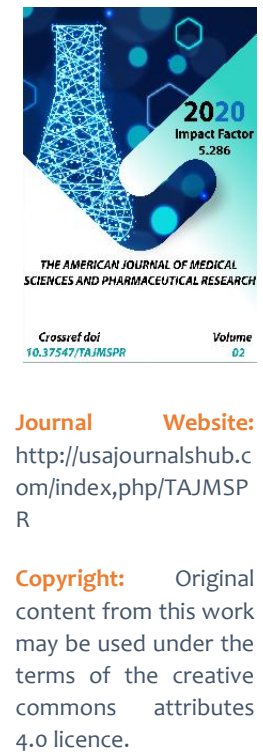

\title{
Somatometric Characteristics Of Women Of The First And Second Period Of Adulthood Using Different Contraceptives With Different Body Types
}

Khamdamova M.T.

Bukhara State Medical Institute named after Abu Ali Ibn Sina. the city of Bukhara, Uzbekistan

\section{ABSTRACT}

This article describes the characteristics of the anthropometric parameters of women of the first and second period of adulthood who use various contraceptives of different weights and physiques-in addition to height and weight, the characteristics of the pelvis size are presented - interosseous, intercostal, intervertebral sizes, external conjugate.

\section{KEYWORDS}

Constitution, somatotype, physique, pelvis, uterus, ovary, contraception, female, dolichomorphic, mesomorphic, brachymorphic, type.

\section{INTRODUCTION}

The preventive direction of modern medicine is based on many fundamental studies. The doctrine of the constitution has a long history. T. S. Sorokina (1992) notes that the creation of the doctrine of the human constitution and its impact on health, the course of diseases is associated with the works of Hippocrates and Galen [1]. These authors paid great attention to the concepts of the constitution and appearance of a person and pointed out a number of diseases peculiar to a particular morphological type. Hippocrates proposed two classifications of constitution al types. The first classification is based on the ratio and predominance of one or another main body juice (blood, mucus, 
yellow and black bile). In this regard Hippocrates distinguished the following types of human constitution: good and bad, strong and weak, dry and wet, elastic and flaccid. The second classification is based on the peculiarities of human temperament and behavior in society. In particular, he divided people into 4 types: choleric, sanguine, phlegmatic and melancholic.

In the world of constitution possible to identify a number of schools (French,German, etc.), which have developed different schemes of constitution al typology [2,3,5] . These schemes are built on different principles and include features that are biologically unequal.

As noted by domestic authors $[4,8]$, the constitution is a set of functional and morphological features of the body, formed on the basis of inherited and acquired properties that determine the originality of the body's response to external and internal stimuli.

G. N.Candelas et al., (2017) believe that the constitution is a multi - disciplinary phenomenon. This phenomenon is based on the study of the variety of physique features of somatotypes. In modern medical anthropology and medicine, the Constitution is evaluated as a complex of individual morphofunctional features of an individual [6].

N. Pende (1922) proposed a classification by predominance functions of one or another endocrine gland.

Foreign anthropology distinguishes between General and particular constitution $s[7,9,10]$. The General constitution - the General, total property of the organism to react in a certain way to the effects of the environment, it is a single principle of the diverse activities of allit is characterized by the functional unity of all physical, physiological and mental properties of the individual. The General constitution determines all the physical, physiological and formal psychological properties of the individual, but they can change depending on the conditions of development and upbringing. The concept of "private constitutions" includes somatotype (a characteristic of the constitution based on morphological criteria), temperament (a psychodynamic characteristic of a person), serological (groups of serological belonging), dermatological and other constitutions.

The issue of the Constitution is closely related to the problem of classification of constitutional types, which causes a large number of different complexity and significance of constitutional schemes.

The body type is the most accessible to research, relatively stable in ontogenesis and genetically determined characteristic of the integrity of the body [11].

The assessment of physical development, General and local constitution, functional state of organs and systems of the body as a whole is considered an integral part of the health characteristic $[8,12]$.

A fundamentally new classification was Sheldon W. D. (1949). In W. G. Sheldon distinguishes between endomorphic, mesomorphic and ectomorphic types, and the components of temperament-visceroSOMATO - and cerebrotonia. The classification was based on the degree of development of germ leaf derivatives. At the same time, Sheldon notes that the somatotype unchanged throughout life. The appearance and size of the body changes, but not the somatotype [10]. 
In 1969, American physiologists B. Heath and L. Carter refined the Sheldon system. English anthropologists widely apply the Parnell scheme (Parnell, 1954), based on the use of the table given in the work of B. Heath (1969). It takes into account three sets of measuring features for representatives of different age groups: height-weight ratios, bone diameters and girth dimensions, as well as skin-fat folds $[2,3]$.

Over time, views on the causes of different human constitution $s$ have also changed. Thus, E. N. Hrisanfova (2002) pointed to the leading influence of the genotype $\mathrm{V}$. P. Alekseyev (1966) pointed to the conditions in which the formation of the organism takes place as a negative effect of the external environment the dominant factor $[1,7]$. Both factors, both genetic predisposition and external conditions, are now recognized.

For women, there are much fewer evaluation schemes, mainly working with the scheme of I. B. GALANT (1927). The author identifies 7 types of constitution, grouped into 3 categories, and emphasizes that the evaluation of the constitution should include psychophysical differences [2].

In medicine and physical education to date (with rare exceptions), the average approach to a person is used without taking into account his constitution al affiliation, which significantly reduces the effectiveness of implemented programs. The problem of the" norm " of morphofunctional indicators, including the size of the pelvis, is also implemented according to the average principle, which is methodologically incorrect.

Thus, there are geographical features of the anthropometric parameters of women with different types of constitution. It is of practical interest to study the features of ultrasound anatomy of the uterus and ovaries in women of the first and second types of Mature age using different contraceptives of the same ethnic-territorial group and different body types.

The purpose of the study was to identify the features of anthropometric characteristics and pelvic shape in women of the first and second period of adulthood using various contraceptives of different body types of the same ethnic and territorial group.

\section{MATERIAL AND METHODS OF RESEARCH}

To solve these tasks, we examined 520 women of the first and second period of adulthood, among whom 480 used various types of contraceptives and 40 women in the control group do not use contraceptives, who were born and permanently live in the city of Bukhara and the Bukhara region belonging to the Uzbek-Tajik ethnic group.

All ethical principles related to the involvement of women in medical research are based on the Helsinki Declaration of the world Medical Association (Helsinki, 1964, last updated, Seoul, 2008).

To characterize the physique types of the examined women of the first and second period of adulthood using various contraceptives, such pelvic dimensions as interosseous, intervertebral, intercostal distances, external conjugate, pelvic width index, as well as height, weight and body mass index were studied.

\section{RESEARCH RESULT}

When assessing the inter-bone size, the average value in women of the first and second periods of adulthood using various contraceptives in the group with a height of $151-160 \mathrm{~cm}$ without dividing into body types 
was $25.5 \pm 1.2 \mathrm{~cm}$, with the maximum value of indicators was $27 \mathrm{~cm}$, and the minimum - 22 $\mathrm{cm}$. In the group of brachiomorphic women of the first and second period of adulthood using various contraceptives with a height of 151-160 $\mathrm{cm}$, the size was $26.5 \pm 0.6 \mathrm{~cm}$ (the minimum value is $25 \mathrm{~cm}$ and the maximum value is 27 $\mathrm{cm})$. In women of the first and second period of adulthood, using various contraceptives of the dolichomorphic type with a height of 151$160 \mathrm{~cm}$, the interosseous size indicators were $23.5 \pm 0.5 \mathrm{~cm}$ with a minimum value of $22 \mathrm{~cm}$, and a maximum value of $24 \mathrm{~cm}$. When evaluating the interosseous size in the group with mesomorphic type in the growth group of $151-160 \mathrm{~cm}$, it was $24.9 \pm 1.1 \mathrm{~cm}$, with a minimum value of $22.5 \mathrm{~cm}$ and a maximum value of $26 \mathrm{~cm}$. Differences in this indicator significantly $\quad(p<0.05) \quad$ increase from dolichophomorphic to mesomorphic and brachymorphic body types.

When assessing the inter-bone size in the group with a height of $161-170 \mathrm{~cm}$ for all body types, the average value was $26.8 \pm 0.2 \mathrm{~cm}$, with a minimum value of $23 \mathrm{~cm}$ and a maximum value of $30 \mathrm{~cm}$. In the group with brachiomorphic type in women of the first and second period of adulthood using various contraceptives with a height of $161-170 \mathrm{~cm}$ the size was $28.9 \pm 1.1 \mathrm{~cm}$ with a minimum value of $26 \mathrm{~cm}$ and a maximum value of $30 \mathrm{~cm}$ In women of the first and second period of adulthood, using various contraceptives with a dolichomorphic type with a height of 161-170 $\mathrm{cm}$, the interosseous size was $25.7 \pm 0.9 \mathrm{~cm}$ with a minimum value of $23 \mathrm{~cm}$, and the maximum value of $27 \mathrm{~cm}$, and in the group with a mesomorphic type with a height of 161 $170 \mathrm{~cm}$ was $26.3 \pm 0.8 \mathrm{~cm}$, with a minimum value of $24 \mathrm{~cm}$ and a maximum value of 27 $\mathrm{cm}$.body type $(\mathrm{p}<0.05)$.
When evaluating the interspin size in the group with a height of $171-180 \mathrm{~cm}$, the average size increased to $27.6 \pm 1.1 \mathrm{~cm}$, with a minimum value of $23 \mathrm{~cm}$ and a maximum value of $29 \mathrm{~cm}$. In the group with brachiomorphic type in women of the first and second period of adulthood using various contraceptives with a height of $171-180 \mathrm{~cm}$, the size was the largest $28.6 \pm 0.4 \mathrm{~cm}$ with a minimum value of $27 \mathrm{~cm}$ and a maximum value of $29 \mathrm{~cm}$. In women of the first and second period of adulthood using various contraceptives with a dolichomorphic type with a height of $171-180 \mathrm{~cm}$, the interbone size was the smallest $-26.4 \pm 1.0 \mathrm{~cm}$ with a minimum value of $23 \mathrm{~cm}$, and the maximum value of $27 \mathrm{~cm}$. In the group with mesomorphic type growth of $171-180 \mathrm{~cm}$, the size was $26.2 \pm 0.7 \mathrm{~cm}$, with a minimum value of $25 \mathrm{~cm}$ and a maximum value of $27 \mathrm{~cm}$.

Thus, with an increase in the growth of women of the first and second period of adulthood using various contraceptives, the interosseous size increased significantly $(p<0.05)$ in each growth group and a reliable $(p<0.05)$ pattern of distribution of the quantitative value of this indicator in the sequence: dolichomorphic-mesomorphicbrachymorphic type was preserved.

When assessing intercostal size, the average value in women of the first and second periods of adulthood using various contraceptives in the group with a height of $151-160 \mathrm{~cm}$ was $27.2 \pm 1.8 \mathrm{~cm}$, with the maximum values of indicators were $30 \mathrm{~cm}$, and the minimum values of $24 \mathrm{~cm}$.

Similarly, the other external size of the pelvis intercostal-changed. When assessing intercostal size in the group with brachiomorphic type in women of the first and second period of adulthood using various contraceptives with a height of $151-160 \mathrm{~cm}$ it was $28.2 \pm 0.9 \mathrm{~cm}$ with a minimum value of 27 
$\mathrm{cm}$ and a maximum value of $30 \mathrm{~cm}$ In women of the first and second period of Mature age using different contraceptives with dolichomorphic type with growth $151-160 \mathrm{~cm}$ indicators migrainepage size was $25.2 \pm 0.5 \mathrm{~cm}$ with a minimum value of $24 \mathrm{~cm}$, and the maximum value is $26 \mathrm{~cm}$ and in the group with mesomorphic type growth $151-160 \mathrm{~cm}$ size was $26.6 \pm 0.8 \mathrm{~cm}$, with a minimum value of $25 \mathrm{~cm}$ and a maximum value of $28 \mathrm{~cm}$ (see figure 2 ).

When assessing intercostal size in the group with a height of 161-170 cm for all body types, the average value was $27.9 \pm 1.5 \mathrm{~cm}$, with a minimum value of $25 \mathrm{~cm}$ and a maximum value of $35 \mathrm{~cm}$. In the group with brachymorphic type in women of the first and second period of adulthood using various contraceptives with a height of $161-170 \mathrm{~cm}$ the size was $29.9 \pm 1.0 \mathrm{~cm}$ with a minimum value of $29 \mathrm{~cm}$ and a maximum value of $35 \mathrm{~cm}$ In women of the first and second period of adulthood using various contraceptives with a dolichomorphic type with a height of $161-170 \mathrm{~cm}$, the intercostal size was $26.2 \pm 0.9 \mathrm{~cm}$ with a minimum value of $25 \mathrm{~cm}$, and the maximum value of $29 \mathrm{~cm}$.

The intercostal size in the group with a mesomorphic body type and height of 161-170 $\mathrm{cm}$ was $27.9 \pm 0.6 \mathrm{~cm}$, with a minimum value of $27 \mathrm{~cm}$ and a maximum value of $29 \mathrm{~cm}$ (figure 2, table 4).

When assessing the intercostal size in the group with a height of $171-180 \mathrm{~cm}$, the average value was $29.6 \pm 1.5 \mathrm{~cm}$, with a minimum value of $25 \mathrm{~cm}$ and a maximum value of $33 \mathrm{~cm}$. In the group with brachymorphic type in women of the first and second period of adulthood using various contraceptives with a height of $171-180 \mathrm{~cm}$ the size was $31.2 \pm 0.7 \mathrm{~cm}$ with a minimum value of $30 \mathrm{~cm}$ and a maximum value of $33 \mathrm{~cm}$ In women of the first and second period of adulthood using various contraceptives of the dolichomorphic type with a height of $171-180 \mathrm{~cm}$, the intercostal size was $27.7 \pm 0.8 \mathrm{~cm}$ with a minimum value of 25 $\mathrm{cm}$, and a maximum value of $29 \mathrm{~cm}$. When assessing the intercostal size in the group with mesomorphic type and height of $171-180 \mathrm{~cm}$, it was $29.4 \pm 0.6 \mathrm{~cm}$, with a minimum value of 29 $\mathrm{cm}$ and a maximum value of $31 \mathrm{~cm}$.

When assessing the intervertebral size, it was found that the average value in women of the first and second periods of adulthood using various contraceptives of all body types in the group with a height of $151-160 \mathrm{~cm}$ was $30.8 \pm 1.7$ $\mathrm{cm}$, with the maximum values of indicators were $35 \mathrm{~cm}$, and the minimum values were 28 $\mathrm{cm}$. In the group with brachymorphic body type in women of the first and second period of adulthood using various contraceptives with a height of $151-160 \mathrm{~cm}$ the size was $32.6 \pm 1.2 \mathrm{~cm}$ with a minimum value of $30 \mathrm{~cm}$ and a maximum value of $35 \mathrm{~cm}$ In a dolichomorphic type with a height of 151-160 $\mathrm{cm}$, the intervertebral size indicators were $29.0 \pm 0.7 \mathrm{~cm}$ with a minimum value of $28 \mathrm{~cm}$, and a maximum value of $31 \mathrm{~cm}$. When evaluating the intervertebral size in a group with a mesomorphic type with a height of 151$160 \mathrm{~cm}$, the size was $30.4 \pm 1.2 \mathrm{~cm}$, with a minimum value of $29 \mathrm{~cm}$ and a maximum value of $34 \mathrm{~cm}$.

When assessing the intervertebral size in the group with a height of $161-170 \mathrm{~cm}$ without dividing into body types, the average value was $31.5 \pm 1.8 \mathrm{~cm}$, with a minimum value of 27 $\mathrm{cm}$ and a maximum value of $38 \mathrm{~cm}$. In the group with brachymorphic type in women of the first and second period of adulthood using various contraceptives with a height of 161-170 $\mathrm{cm}$ the size was $33.0 \pm 1.1 \mathrm{~cm}$ with a minimum value of $32 \mathrm{~cm}$ and a maximum value of $38 \mathrm{~cm}$ In women of the first and second period of adulthood using various contraceptives with a 
dolichomorphic body type and a height of 161 $170 \mathrm{~cm}$, the intervertebral size was $29.6 \pm 1.5 \mathrm{~cm}$ with a minimum value of $27 \mathrm{~cm}$, and a maximum value of $34 \mathrm{~cm}$. When evaluating the intervertebral size in the group with mesomorphic type and height of $161-170 \mathrm{~cm}$, it was $31.8 \pm 1.0 \mathrm{~cm}$, with a minimum value of 30 $\mathrm{cm}$ and a maximum value of $34 \mathrm{~cm}$.

When evaluating the intervertebral size in the group with a height of $171-180 \mathrm{~cm}$, the average size was $33.2 \pm 1.3 \mathrm{~cm}$, with a minimum value of $29 \mathrm{~cm}$ and a maximum value of $36 \mathrm{~cm}$. In the group with brachymorphic type in women of the first and second period of adulthood using various contraceptives with a height of 171-180 $\mathrm{cm}$ the size was $33.8 \pm 0.7 \mathrm{~cm}$ with a minimum value of $33 \mathrm{~cm}$ and a maximum value of $36 \mathrm{~cm}$ In women of the first and second period of adulthood using various contraceptives with a dolichomorphic type with a height of 171-180 $\mathrm{cm}$, the intervertebral size was $31.4 \pm 1.6 \mathrm{~cm}$ with a minimum value of $29 \mathrm{~cm}$, and the maximum value of $36 \mathrm{~cm}$. When assessing the intervertebral size in the group with mesomorphic type and height of $171-180 \mathrm{~cm}$, it was $33.5 \pm 1.5 \mathrm{~cm}$, with a minimum value of 31 $\mathrm{cm}$ and a maximum value of $36 \mathrm{~cm}$.

In the evaluation of the external conjugates mean value in women of the first and second period of Mature age using different contraceptives all body types in the group with growth $151-160 \mathrm{~cm}$ it was $20.9 \pm 1.0 \mathrm{~cm}$, while the maximum values were $22 \mathrm{~cm}$ and a minimum value of 17 see

When evaluating external conjugates in the group with brachymorphic type in women of the first and second period of adulthood using various contraceptives with a height of 151-160 $\mathrm{cm}$ the size was $20.7 \pm 0.8 \mathrm{~cm}$ with a minimum value of $18.5 \mathrm{~cm}$ and a maximum value of 22 $\mathrm{cm}$ In women of the first and second period of adulthood using various contraceptives with a dolichomorphic type with a height of 151-160 $\mathrm{cm}$, the external conjugate indicators were $19.0 \pm 0.8 \mathrm{~cm}$ with a minimum value of $17 \mathrm{~cm}$, and a maximum value of $21 \mathrm{~cm}$. When evaluating the size of the external conjugate in the group with mesomorphic type and height of $151-160 \mathrm{~cm}$, the size was $19.7 \pm 0.8 \mathrm{~cm}$, with a minimum value of $18 \mathrm{~cm}$ and a maximum value of $21 \mathrm{~cm}$.

When assessing the size of the external conjugate in the group with a height of 161-170 $\mathrm{cm}$, the average value without dividing into body types was $20.5 \pm 1.2 \mathrm{~cm}$, with a minimum value of $18 \mathrm{~cm}$ and a maximum value of $24 \mathrm{~cm}$. When assessing the size of the external conjugate in the group with brachymorphic type in women of the first and second period of adulthood using various contraceptives with a height of $161-170 \mathrm{~cm}$ the size was $21.4 \pm 0.9 \mathrm{~cm}$ with a minimum value of $20 \mathrm{~cm}$ and a maximum value of $24 \mathrm{~cm}$ In women of the first and second period of adulthood using various contraceptives with a dolichomorphic type with a height of $161-170 \mathrm{~cm}$, the external conjugate was $19.5 \pm 1.0 \mathrm{~cm}$ with a minimum value of $18 \mathrm{~cm}$, and the maximum value of 22 $\mathrm{cm}$.

When evaluating the size of the external conjugate in the group with mesomorphic type and height of $161-170 \mathrm{~cm}$, the size was $20.6 \pm 0.8 \mathrm{~cm}$, with a minimum value of $19 \mathrm{~cm}$ and a maximum value of $22 \mathrm{~cm}$.

When evaluating the size of the external conjugate in a group with a height of $171-180$ $\mathrm{cm}$

The average size for all body types was $21.1 \pm 0.9 \mathrm{~cm}$, with a minimum value of $18 \mathrm{~cm}$ and a maximum value of $24 \mathrm{~cm}$. At the same time, when assessing the size of the external conjugate in the group with brachymorphic type in women of the first and second period 
of adulthood using various contraceptives with a height of $171-180 \mathrm{~cm}$, the size was $21.4 \pm 0.7 \mathrm{~cm}$ with a minimum value of $19 \mathrm{~cm}$ and a maximum value of $22 \mathrm{~cm}$. In women of the first and second period of adulthood using various contraceptives with a dolichomorphic type with a height of $171-180 \mathrm{~cm}$, the size of the external conjugate was $21.4 \pm 1.1 \mathrm{~cm}$ with a minimum value of $18 \mathrm{~cm}$ and a maximum value of $24 \mathrm{~cm}$. When evaluating the size of the external conjugate in the group with mesomorphic type and height of $171-180 \mathrm{~cm}$, the size was $21.2 \pm 0.7 \mathrm{~cm}$, with a minimum value of $20 \mathrm{~cm}$ and a maximum value of $22 \mathrm{~cm}$.

\section{CONCLUSION}

Thus, it was found that women of the first and second periods of adulthood who use various contraceptives with a significant increase in the average value of pelvic distances as the growth increases in groups $(151-160 \mathrm{~cm}$; 161 $170 \mathrm{~cm} ; 171-180 \mathrm{~cm}$ ), there is also a trend of a significant increase in these pelvic sizes from dolifomorphic to mesomorphic and then to brachymorphic body types.

\section{REFERENCES}

1. Alexandrovich V., Jerzy A. V, Krzysztof G. 2016. "Telocytes in the female reproductive system (human and animal). - Journal of cellular and molecular medicine. https://doi.org/10.1111/jcmm.12843.

2. Asensio R. L., Manuel A. G., Alberto P.G., Juan A., Juanes M. 2019. "Computer application of ultrasound and nuclear magnetic resonance images for the anatomical study of the pelvis and female pelvic floor. - Journal of medical systems. https://doi.org/10.1007/s10916-019-1240-6.

3. Balaya V., Ukhl Zh., Lanore A., Salachas S., Samoyeau T., Ngo S., Bensaid, S., et al. 2016. "3D modeling of the female pelvis by computer anatomical dissection: application and prospects."Journal de Gynecologie Obstetrique et Biologie de La Reproduction.

https://doi.org/10.1016/j.jgyn.2016.01.006.

4. Betty L., Noreen T., Andrea M., Steven J. 2014. "Interaction of neutral evolutionary processes with climate-induced adaptive changes in the three-dimensional form of the human body Os Coxae. - Journal of human evolution. https://doi.org/10.1016/j.jhevol.2014. 02.021.

5. Brown K. M. 2015. "Selective pressure in the human pelvis: separation of sexual dimorphism in the anterior and posterior spaces. - American journal of physical anthropology.

https://doi.org/10.1002/ajpa.22734.

6. Candelas G. N., Josefina R. P., Beatriz Ch., Oscar C., Armando G. M. 2017. "Geometric Morphometry reveals limitations on the shape of female coxae wasps. - Journal of anatomy. https://doi.org/10.1111/joa.12528.

7. Desilva J. M., Karen R. R., 2017. - Anatomy, development and functions of the human pelvis.- Anatomical Reference. https://doi.org/10.1002/ar.23561.

8. Gruss L.T., Richard G. Daniel S. 2017. - Pelvic width and Locomotor kinematics in human evolution.- Anatomical Reference. https://doi.org/10.1002/ar.23550.

9. Kurki H. K., Sarah L. D. 2016. "Changing the shape of the human pelvis and limb skeleton: implications for obstetric adaptation. - American journal of physical anthropology.

https://doi.org/10.1002/ajpa.22922.

10. Kraima A., Smith N., Jansma D., Eisemann E., Park S. G., Chang S. M., West N., et al. 2015. "Developing a 3D anatomical Atlas of the pelvis: the next step in improving surgical anatomical education and clinical guidance. - European journal of Oncology. 
Doi: https://doi.org/10.37547/TAJMSPR/Volume02Issue08-10

11. Khamdamova M. T. Ultrasound assessment of changes in the endometrium of the uterus in women of the first and second period of middle age when using intrauterine and oral contraceptives. Journal of Biomedicine and practice special issue-2 Tashkent-2020 issn 2181-9300 https://doi magazine 10.26739/2181-9300.

12. Wall-Scheffler, Kara M., Marcella J.M. 2017. "Biomechanical and energy advantages of a medial-Lateral broad pelvis in women. Anatomical Reference. https://doi.org/10.1002/ar.23553. 